\title{
PERCEPÇÃO AMBIENTAL SOBRE ARBORIZAÇÃO URBANA EM REGIÕES DISTINTAS DO MUNICÍPIO DE BAURU-SP
}

\author{
ENVIRONMENTAL PERCEPTION ABOUT URBAN FORESTS IN DISTINCT AREAS \\ OF THE MUNICIPALITY OF BAURU-SP
}

Marcela Carolina Souza Sufia', Gabriela dos Santos Souza², Marcos Vinicius Bohrer Monteiro Siqueira³

\section{RESUMO}

A arborização urbana compreende toda e qualquer vegetação arbórea em espaços públicos e privados de uma cidade. Quando executada com planejamento adequado, pode gerar benefícios nos âmbitos ecológico e social. Com o objetivo de comparar a percepção ambiental dos moradores em relação à arborização urbana do município de Bauru-SP, foram selecionados dois bairros em regiões distintas da cidade. Em cada uma das áreas, aplicou-se um questionário com questões abertas e fechadas a 106 participantes escolhidos de forma aleatória, no qual pretendeu-se determinar o perfil dos entrevistados, bem como a opinião destes em relação à arborização do seu bairro, suas vantagens e desvantagens, a responsabilização do manejo das árvores, entre outros. Os resultados obtidos indicaram que, no bairro situado na zona sul da cidade, a maioria (59\%) dos entrevistados sabe o significado de arborização urbana e demonstra interesse em contribuir financeiramente para ações de plantio e manutenção, enquanto que no bairro localizado na região norte, a minoria (38\%) possui algum conhecimento sobre o assunto, apresentando uma menor disponibilidade para melhorias na arborização do bairro. A percepção da arborização entre os bairros foi distinta, sendo que 59\% dos moradores do bairro Parque Jardim Europa mostraram conhecimento sobre arborização, contra $38 \%$ do bairro Parque Santa Edwiges, e algumas dessas razões podem ser derivadas da ação do poder público local, do grau de instrução dos moradores, poder aquisitivo entre outros fatores.

Palavras-chave: Qualidade de vida; Planejamento Urbano; Vias públicas.

\begin{abstract}
The term urban forest comprises any vegetation landscape in a city, both in public and private areas. When executed with an appropriate planning, urban forests can generate ecological and social benefits. The purpose of this study is to compare the environmental perception about urban forests by residents from two neighborhoods selected in of different regions of Bauru-SP. In each area, a questionnaire with open and closed questions was applied to 106 participants in order to identify the their profile, as well as their opinion about topics such as urban forests presence, its advantages and disadvantages, management practices for tree care and others. The majority of respondents from the south region (59\%) affirmed to understand urban forest's meaning and demonstrated more interest in to contribute with financial support to planting and management actions, while only $37 \%$ of the participants from the north region were aware about the subject and less interested in neighborhood urban forests improvements. Therefore the distinctive perception of urban forests among neighborhoods residents could be explained by the difference public policy initiatives in each region, resident's schooling, socioeconomic power and others.
\end{abstract}

Keywords: Quality of life; Public roads; Urban planning.

Recebido em 23.02.2019 e aceito em 05.04.2019

${ }^{1}$ Graduada em Ciências Biológicas. Universidade do Sagrado Coração. Bauru /SP. Email: marcelasufia@gmail.com

2 Engenharia Agronômica. Especialista em Meio Ambiente na Secretaria do Meio Ambiente. Bauru/SP. Email: gaby_souza1@hotmail.com

3 Doutor em Ecologia Aplicada. Docente na Faculdade de Ensino Superior e Formação Integral. Garça/SP. Email: mvbsiqueira@gmail.com 


\section{INTRODUÇÃO}

Devido ao avanço da industrialização, muitas pessoas migraram para os centros urbanos em busca de emprego, aumentando consideravelmente o número de residentes das áreas urbanas nas últimas décadas. Desde então, as atividades humanas, o uso excessivo de recursos naturais, a introdução de espécies invasoras, a poluição, entre outros, interferem nos ambientes naturais sem calcular as consequências futuras, favorecendo, assim, o crescimento desordenado e sem planejamento das cidades (RODRIGUES et al., 2010).

Segundo índices do IBGE (2017), na década de 1950, cerca de 63\% dos habitantes do Brasil moravam em áreas rurais. Com a potencialização da indústria, o cenário mudou e, na década de 1970, o país já possuía $84 \%$ das pessoas vivendo nos centros urbanos. O município de Bauru, localizado no centro-oeste do Estado de São Paulo, seguiu a tendência nacional, pois a maioria dos moradores migrou para as áreas urbanas. O município conta, atualmente, com aproximadamente 371.690 habitantes, conforme dados mais recentes do IBGE (2017). Deste total, ainda segundo o levantamento realizado pelo órgão federal, cerca de $98 \%$ da população local vive em área urbana.

Para proporcionar a expansão urbana, muitas áreas foram desmatadas, gerando diversas interferências no sistema natural, como o aumento de ruídos, da poluição, intensificação de enchentes, alterações microclimáticas, mudanças do uso do solo, desarmonia paisagística, entre outros (SOUZA; CARDOSO; SILVA, 2013). Por esses motivos, é evidente a necessidade de planejamento para a ocupação do meio urbano, que considere a arborização urbana como um ponto relevante, pois, quando planejada de forma correta, pode diminuir os impactos que essas interferências causam na população.

A arborização urbana compreende toda e qualquer vegetação arbórea que esteja localizada em espaços públicos e privados de uma cidade, com diversas vantagens para seus moradores (PINHEIRO; SOUZA, 2017). Quando executada com planejamento adequado, pode gerar inúmeros benefícios, como, por exemplo, a melhoria do microclima associado ao sombreamento; diminuição da temperatura; aumento da umidade relativa e filtragem do ar; proteção do solo através do enraizamento das árvores; diversidade da flora e fauna; redução do nível de ruído, entre outros. Além dos benefícios ecológicos, destaca-se a importância social, como a melhoria da qualidade de vida, por meio da diminuição da monotonia dos ambientes, devido às diferentes cores, formas, texturas e aromas existentes. Há, ainda, melhora nos aspectos físicos, reduzindo o número de pessoas com doenças respiratórias, pois a arborização urbana aumenta a qualidade do ar e diminui o estresse, 
resultados do maior convívio com a natureza (MOSER et al., 2010).

Ainda no que diz respeito à humanização dos espaços, a arborização presente na área urbana, além de valorizar a estética e satisfazer aspectos sociais e econômicos, proporciona também um clima diferenciado e, consequentemente, mais agradável (OLIVEIRA et al., 2017).

Conforme Rodrigues et al. (2010), se não houver o reconhecimento da importância da arborização das áreas urbanas, será comum o fracasso dos plantios ou da manutenção desses espaços, podendo ser justificado, principalmente, pela falta de envolvimento da população e também pela ausência de sensibilização sobre a arborização. Isso porque, para um planejamento eficiente em relação à manutenção da arborização, é preciso levar em conta, entre múltiplos fatores, a percepção ambiental dos moradores locais.

Embora haja diversos estudos sobre a percepção ambiental relacionada à arborização urbana, (GROSS et al., 2012; SILVA et al., 2015; LOURENÇO, 2017), análises qualiquantitativas, como as realizadas no presente trabalho, podem propiciar o envolvimento da população e das políticas públicas com as questões de planejamento ambiental da cidade. Estudos de percepção ambiental sobre arborização urbana devem ser levados em consideração não somente pelo embasamento e apoio à gestão da arborização urbana, mas, também, por causar reflexão em quem reside no local, visto que são eles que sentem diretamente o impacto da qualidade ambiental a partir da manutenção da biodiversidade nos diferentes bairros (QUADROS; FREI, 2009; RODRIGUES et al., 2010).

Visto que não há reflexos na literatura de estudos realizados junto aos bauruenses sobre a percepção da arborização urbana, o presente trabalho teve como objetivo analisar a percepção ambiental dos moradores de diferentes bairros do município de Bauru-SP.

\section{MATERIAL E MÉTODOS}

\section{Descrição do local de estudo}

O estudo foi realizado no município de Bauru, que está localizado ao Centro-Oeste do Estado de São Paulo, entre as coordenadas geográficas 22¹8'54" S e 4903'39" O, com altitude máxima de $615 \mathrm{~m}$ e mínima de $490 \mathrm{~m}$ acima do nível do mar. O clima é, segundo classificação de Koppen, do tipo Cwa subtropical com chuvas de verão e inverno relativamente seco. A vegetação nativa é formada basicamente por Cerrado e Floresta Estacional Semidecidual. O município abrange uma área de $673 \mathrm{~km}^{2}$ e uma população de 371.690 habitantes, segundo dados do IBGE (2017). 
Para o presente estudo, foram selecionados dois bairros, sendo eles o Parque Santa Edwiges e o Parque Jardim Europa. O Parque Santa Edwiges está localizado na periferia da região norte do município, que é caracterizada pela construção de moradias populares. O bairro Parque Jardim Europa, que está inserido na região sul do município ou "Altos da Cidade", como é conhecido pelos bauruenses, tem maior concentração de moradias de alto padrão.

As vias locais e imóveis selecionados para compor a área de estudo de cada bairro foram escolhidas de forma aleatória, bem como os indivíduos entrevistados, em um total de 106 informantes, em cada um dos bairros. Procurou-se entrevistar, no mínimo, um morador por rua, de cada bairro. Deste modo, conseguiu-se abranger toda a área de ambos os bairros, tanto do Parque Santa Edwiges quanto do Parque Jardim Europa. De acordo com dados secundários do IBGE (2010), disponíveis pela ferramenta Sinopse por Setores, no Censo de 2010 o Parque Jardim Europa possuía 5081 moradores distribuídos em 1889 domicílios, enquanto que o Parque Santa Edwiges possuía 5639 moradores e 1660 domicílios.

O critério de escolha dos participantes foi, essencialmente, ter idade igual ou superior a 18 anos. Nesses locais, cada entrevistado respondeu um questionário estruturado com 17 questões abertas ou fechadas (Figura 1). As perguntas foram realizadas pelo entrevistador e explicadas novamente quando necessário, porém, sem dar exemplos, para que as respostas não fossem influenciadas. A coleta dos dados ocorreu durante os meses de setembro e outubro de 2018 e, metodologicamente, foi baseada nos estudos de Silva et al. (2014) e Santos et al. (2018).

Depois de realizadas as entrevistas, os dados obtidos foram processados em planilha do aplicativo software Microsoft Excel 2010 tendo sido obtidas as frequências absolutas para as diferentes questões. 


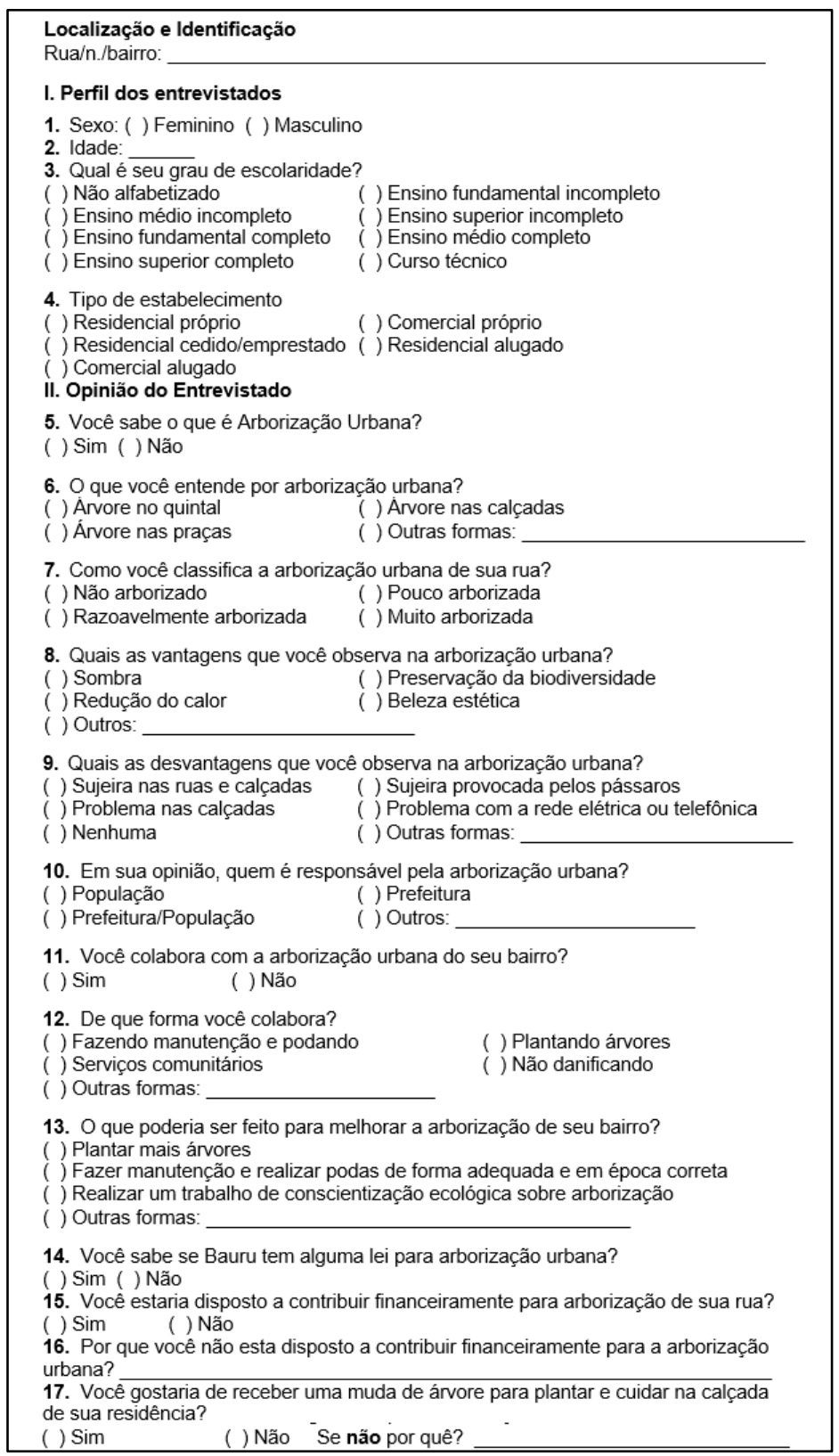

Figura 1 - Formulário de avaliação da percepção ambiental em dois bairros da cidade de Bauru-SP Figure 1 - Evaluation form of environmental awareness regarding in the two districts of the city of Bauru-SP

\section{RESULTADOS E DISCUSSÃO}

A maioria dos entrevistados foi do sexo feminino, correspondendo a um percentual de $58 \%$ dos entrevistados no bairro Parque Santa Edwiges e $71 \%$ dos entrevistados no Parque Jardim Europa. Entre os participantes, há moradores de 18 a 88 anos. Porém, a maioria, em ambos os bairros, apresentou faixa etária compreendida em mais de 50 anos, sendo $47 \%$ no Parque Santa Edwiges e 58\% no Parque Jardim Europa (Tabela 1). 
Sobre a condição de moradia, constatou-se que, no bairro Parque Santa Edwiges, $74 \%$ das residências são próprias, $18 \%$ são alugadas, $7 \%$ são imóveis comerciais e somente duas pessoas moram em imóveis cedidos, o que equivale a $2 \%$ (Tabela 1). A condição de moradia no bairro Parque Jardim Europa seguiu o mesmo contexto, sendo 78\% de residências próprias, $13 \%$ alugadas, $8 \%$ imóveis comerciais (próprio ou alugado) e somente uma pessoa mora em imóvel cedido (1\%). Estas informações tornam-se pertinentes ao se ter em conta que, aproximadamente $75 \%$ dos moradores de ambos os bairros, possuem residência fixa. Possivelmente, pode existir uma percepção mais ampla sobre a arborização do bairro quando as residências são próprias, tendo em vista que o morador que adquire imóvel em determinada localidade, o faz com ânimo definitivo (intenção de permanecer) e, portanto, zela pelo seu bem-estar, inteirando-se das comodidades locais e de tudo que o cerca.

Em relação ao grau de escolaridade dos entrevistados (Tabela 1), no bairro Parque Santa Edwiges, 3\% têm Ensino Superior, 6\% Ensino Superior incompleto, 33\% Ensino Médio completo, 6\% Ensino Médio incompleto, 8\% Ensino Fundamental completo, 39\% possuem Ensino Fundamental incompleto e 6\% não são alfabetizados. Em contrapartida, no Parque Jardim Europa, 43\% têm Ensino Superior, 3\% Ensino Superior incompleto, 27\% Ensino Médio completo, 7\% Ensino Fundamental completo, 19\% possuem Ensino Fundamental incompleto, e 1\% não são alfabetizados. O grau de escolaridade pode tornarse um dos itens interessantes para identificar o corpo dos entrevistados e possibilitar alguma correlação com o nível de instrução e a arborização urbana dos moradores. A falta ou o baixo nível de escolaridade pode não estar diretamente associado à percepção da arborização, no entanto, pode influenciar um certo grau de dificuldade dos entrevistados em responder a questões mais complexas, como definir espécies arbóreas, entre outros (ROPPA et al.; 2007).

Quando questionados sobre "o que é arborização urbana", 38\% dos entrevistados do bairro Parque Santa Edwiges sabiam ou já tinham ouvido falar sobre o termo. Aos $62 \%$ dos pesquisados que não souberam responder foi explicado o significado do conceito. Feito isso, todos os participantes foram indagados a respeito da "classificação da arborização" da rua onde moram e $43 \%$ dos moradores consideram pouco arborizada, $27 \%$ razoavelmente arborizada, e 30\% muito arborizada (dados não amostrados). Já no bairro Parque Jardim Europa, quando questionados sobre "o que é arborização", 59\% dos entrevistados têm conhecimento acerca do assunto. Aos $41 \%$ dos pesquisados que não souberam responder foi explicado o significado do conceito. 
Tabela 1. Perfil socioeconômico dos entrevistados das áreas avaliadas do município de Bauru-SP Table 1. Socioeconomic profile of the respondents from the evaluated areas of the municipality of Bauru-SP

Parque Santa Edwiges (\%) Parque Jardim Europa (\%)

\begin{tabular}{|c|c|c|}
\hline \multicolumn{3}{|l|}{ Gênero } \\
\hline Masculino & 42 & 29 \\
\hline Feminino & 58 & 71 \\
\hline \multicolumn{3}{|l|}{ Faixa etária } \\
\hline Entre 18 e 30 & 23 & 8 \\
\hline Entre 31 e 40 & 13 & 13 \\
\hline Entre 41 e 50 & 17 & 21 \\
\hline Mais que 50 & 47 & 58 \\
\hline \multicolumn{3}{|l|}{ Estabelecimento } \\
\hline Residência própria & 75 & 79 \\
\hline Residência alugada & 17 & 13 \\
\hline Comércio & 8 & 8 \\
\hline \multicolumn{3}{|l|}{ Escolaridade } \\
\hline $\mathrm{EFC}^{*}$ & 8 & 7 \\
\hline $\mathrm{EFI}^{*}$ & 39 & 19 \\
\hline $\mathrm{EMC}^{*}$ & 33 & 27 \\
\hline $\mathrm{EMI}^{*}$ & 6 & 0 \\
\hline $\mathrm{ESC}^{*}$ & 3 & 43 \\
\hline $\mathrm{ESI}^{*}$ & 6 & 3 \\
\hline$N A^{*}$ & 5 & 1 \\
\hline
\end{tabular}

Seguidamente, todos os participantes foram indagados a respeito da "classificação da arborização da rua onde moram", tendo sido essa classificação atribuída a partir do questionário aplicado (Figura 1). No total, 35\% dos moradores consideram pouco arborizada, 38\% razoavelmente arborizada e $27 \%$ muito arborizada. Observou-se que a percepção quanto à quantidade de árvores divergiu nos dois bairros em que a pesquisa foi realizada. No Parque Santa Edwiges, o maior percentual, 43\%, se concentrou na escassez de arborização, enquanto que no Parque Jardim Europa a maioria, 38\%, apontou que a arborização é regular (Figura 2). Cabe enfatizar que 39\% dos entrevistados dos dois bairros declaram haver pouca arborização. Isso demostra o interesse desses moradores por um maior número de árvores nos seus bairros, semelhantemente aos resultados encontrados por Gross et al. (2012), em Lages, SC. Importante também sublinhar que a quantidade de árvores (muito, razoável ou pouca) não está embasada em nenhum levantamento quantitativo, mas na percepção individual de cada entrevistado(a). 


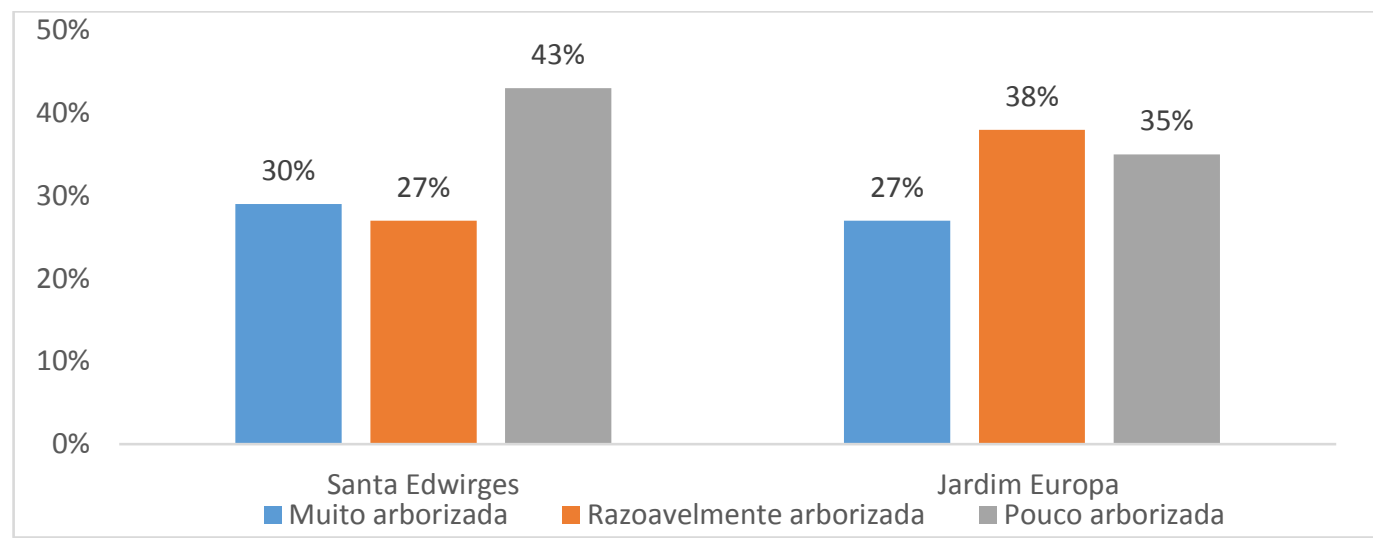

Figura 2 - Percepção dos entrevistados quanto à quantidade de árvores nos dois bairros avaliados da cidade de Bauru-SP

Figure 2 - Perception of the respondents about the quantity of trees in the two evaluated neighborhood in the city of Bauru-SP

Durante as entrevistas, foi possível compreender um pouco mais sobre a visão dos moradores em relação à arborização urbana de seus bairros, e fazê-los refletir sobre algumas questões relacionadas ao assunto. Mais da metade dos entrevistados (51\%), quando questionados sobre como era a arborização de suas respectivas ruas, ou não sabiam responder ou apresentavam dificuldades nas respostas. Em várias ocasiões, os entrevistados precisavam parar e olhar ao redor, demorando inclusive no fornecimento das respostas. Isso evidenciou como é necessária uma maior discussão e reflexão sobre o assunto, visto que a arborização urbana para esses entrevistados é um tema secundário no seu cotidiano. Segundo Oliveira et al. (2017), quando alguém é questionado de algo que não costuma enxergar em seu dia a dia, o assunto gera a oportunidade de reflexão sobre atitudes, conceitos e relevância para um coletivo, o que é exatamente atribuído à arborização urbana no contexto deste estudo.

A percepção da maioria dos entrevistados do Parque Santa Edwiges (37\%) e do Parque Jardim Europa (62\%), que declarou saber o que é arborização urbana, limitava-se às árvores plantadas nas calçadas, não levando em consideração praças e nem árvores nos quintais. Em contrapartida, a população entrevistada em Patos-PB demonstrou, segundo Souza et al. (2016), grande conhecimento sobre a importância da arborização nas praças da cidade, e a contribuição da vegetação na melhoria das condições climáticas locais.

No que se refere às vantagens da arborização, as mais mencionadas pelos participantes dos dois bairros investigados foram sombreamento (62\%), melhoria da qualidade do ar (55\%) e redução do calor (37\%) (Figura 3). Segundo Roppa et al. (2007) e Silva et al. (2015), o fato de os entrevistados considerarem que as "vantagens da arborização" consistem em sombra e redução do calor evidencia que os moradores sentem a necessidade de melhoria do microclima urbano e conforto térmico. Ao analisarem dois 
bairros da cidade de Ubá-MG, Pizziolo et al. (2014) destacaram que a população não possui conhecimento sobre todos os benefícios que a arborização pode trazer para a qualidade de vida no perímetro urbano, só conseguindo reconhecer a formação de sombra e a redução do calor.

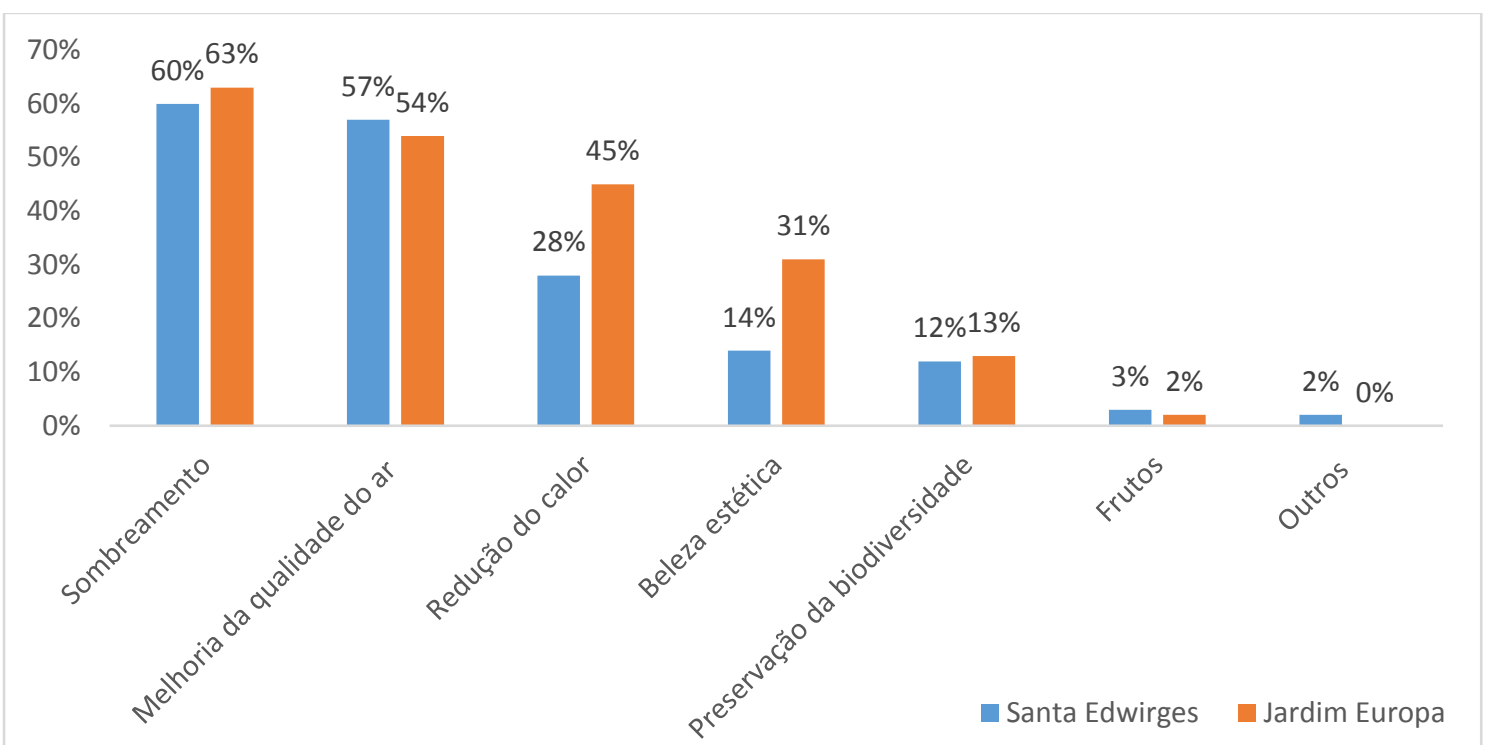

Figura 3 - Vantagens da arborização urbana observadas pelos moradores dos dois bairros avaliados da cidade de Bauru-SP

Figure 3 - Advantages of urban forest observed by the residents of the two evaluated neighborhoods in the city of Bauru-SP

Quando questionados sobre a existência de "desvantagens na arborização", as mais citadas, em ambos os bairros, foram sujeira (31\%), seguida de problemas nas calçadas (9\%) e problemas com a rede elétrica (7\%) (Figura 4). Porém, a maioria considera não haver desvantagem (51\%).

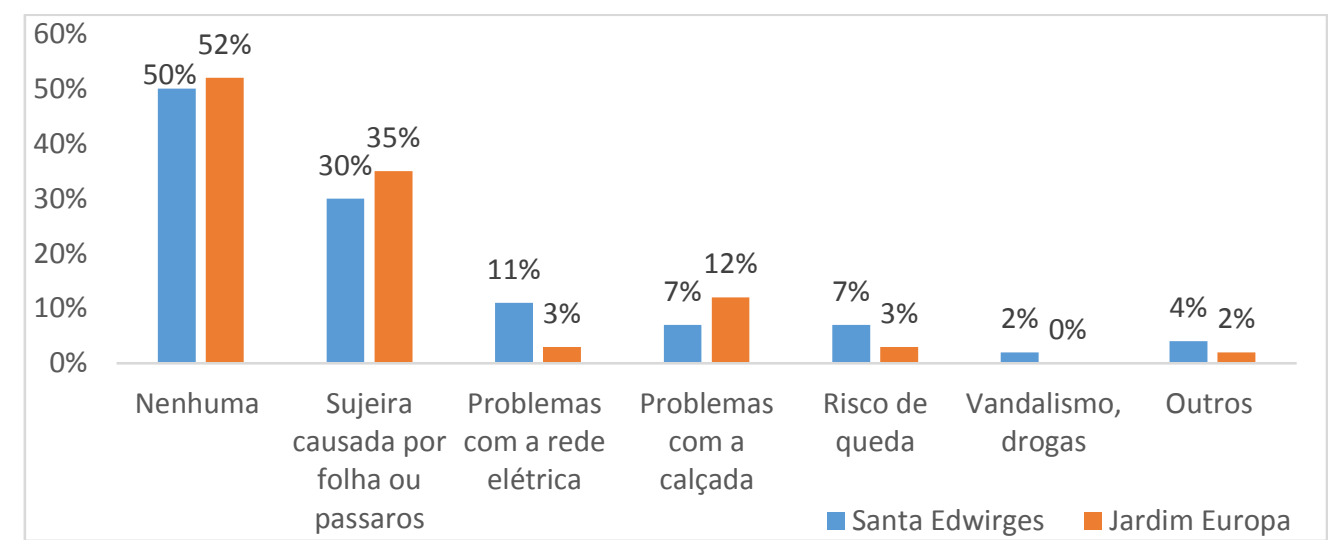

Figura 4 - Desvantagens da arborização urbana observadas pelos moradores dos dois bairros avaliados da cidade de Bauru-SP

Figure 4 - Disadvantages of urban forest observed by the residents of the two evaluated neighborhood in the city of Bauru-SP 
De acordo com os estudos realizados por Souza, Cardoso e Silva (2013), a sujeira nas ruas e calçadas, causada principalmente pela senescência das folhas, foi mencionada como principal desvantagem, o que assemelha aos dados obtidos no presente trabalho. Um dos aspectos negativos realçados pelos entrevistados do bairro Parque Santa Edwiges, em relação às desvantagens da arborização, refere-se às práticas de vandalismo (não mencionado no outro bairro), como a quebra e roubo de novas mudas, retirada dos suportes e proteções das árvores, cortes no tronco, e o uso da sombra da árvore por pessoas desconhecidas, até mesmo para o uso de drogas.

No bairro Parque Santa Edwiges, quando questionados de quem é a responsabilidade pela arborização urbana, 30\% acreditam ser um dever tanto da prefeitura quanto da população, enquanto $28 \%$ entendem que o compromisso é somente da prefeitura, e $39 \%$ apenas da população. Por fim, 1\% não souberam dizer a quem é atribuído o cuidado. No Parque Jardim Europa, 32\% dos entrevistados atribuem que há uma responsabilidade mútua entre prefeitura e população. Do restante pesquisado, 40\% apontam que é encargo da prefeitura, $25 \%$ somente da população e 1\% declararam não saber.

Verificou-se que a maioria dos indivíduos amostrados (39\%) no bairro Parque Santa Edwiges acredita que o principal responsável por desenvolver projetos de arborização nas ruas da cidade é somente a população, enquanto que no Parque Jardim Europa, a maioria dos participantes da pesquisa (32\%) identificou que a responsabilidade deve ser compartilhada (prefeitura municipal e população). $O$ desconhecimento quanto à responsabilidade do órgão municipal na escolha das espécies adequadas colabora para que ocorram plantios pelos moradores, sem o devido conhecimento técnico, situação verificada no Parque Santa Edwiges. Sobre essa questão, Bobrowski e Biondi (2016) destacaram que somente com a corresponsabilidade entre órgão público e a população é possível alcançar o sucesso na arborização urbana. Para isso, a população deve entender a importância da arborização, o custo para a manutenção e a necessidade de impedir atos de vandalismo, como acontece, mesmo em pequena escala, no bairro Parque Santa Edwiges. Shams, Giacomeli e Sucomine (2009) sublinham que arborizar uma cidade requer planejamento e fazê-lo sem critérios pode trazer prejuízos tanto para o poder público quanto à população, como o afloramento de raízes prejudicando construções e calçadas, interferências na fiação elétrica, entre outras situações, problemas estes identificados principalmente no Parque Santa Edwiges.

Dos 106 entrevistados do bairro Parque Santa Edwiges, 42\% afirmam colaborar com a arborização do bairro, enquanto que no Jardim Europa $72 \%$ dos participantes disseram que contribuem para manter o local arborizado. Dentre as ações mencionadas, as 
mais citadas em ambos os bairros foram o plantio (39\%), a manutenção e a poda (37\%) (Figura 5). Em relação à poda, é muito comum, no País, observar moradores realizando podas incorretas. Oliveira et al. (2017) destacam que somente pessoas habilitadas e treinadas devem executá-la, para assim prevenir danos ao meio físico e até mesmo possíveis acidentes.

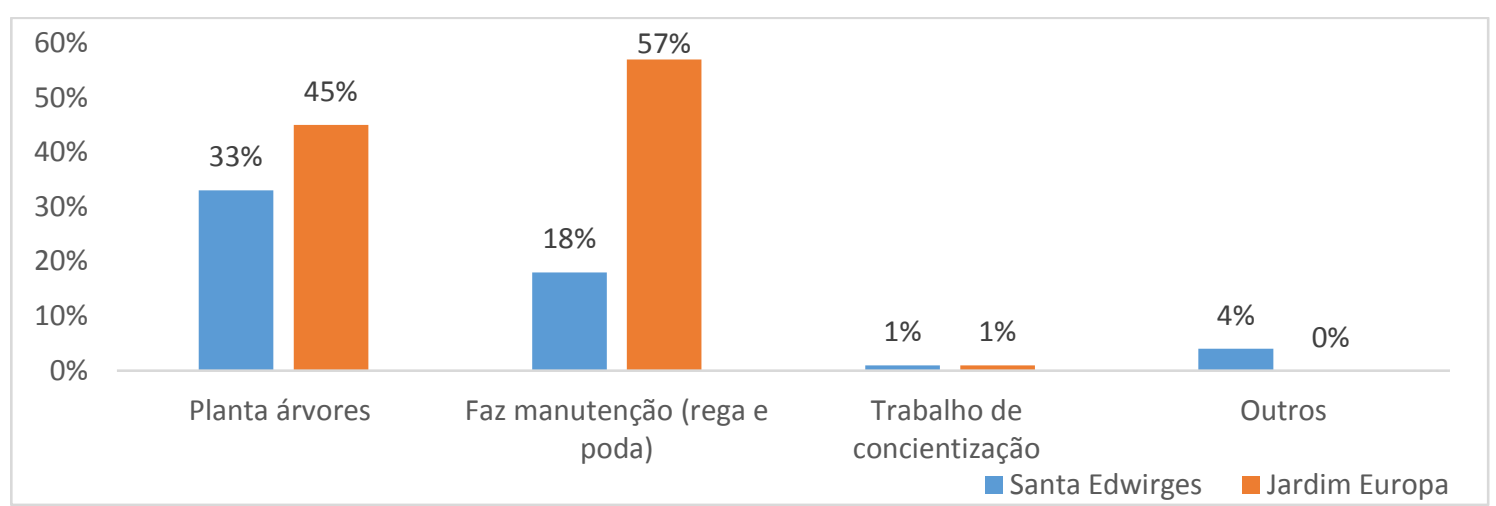

Figura 5 - Formas de colaboração dos entrevistados da cidade de Bauru-SP

Figure 5 - Means of collaboration by the respondents from the city of Bauru-SP

Outro aspecto analisado foi o que a população acredita que poderia ser feito para melhorar a arborização do local. No Parque Santa Edwiges, as medidas mais citadas foram: a necessidade de mais árvores no bairro (55\%), manutenção e poda adequada (34\%) e trabalho de sensibilização com a população (14\%). Já no Parque Jardim Europa, as providências mais apontadas seguem a mesma ordem: necessidade de mais árvores no bairro (49\%), carência de manutenção e poda adequada (33\%), e trabalho de sensibilização com a população (31\%) (Figura 6).

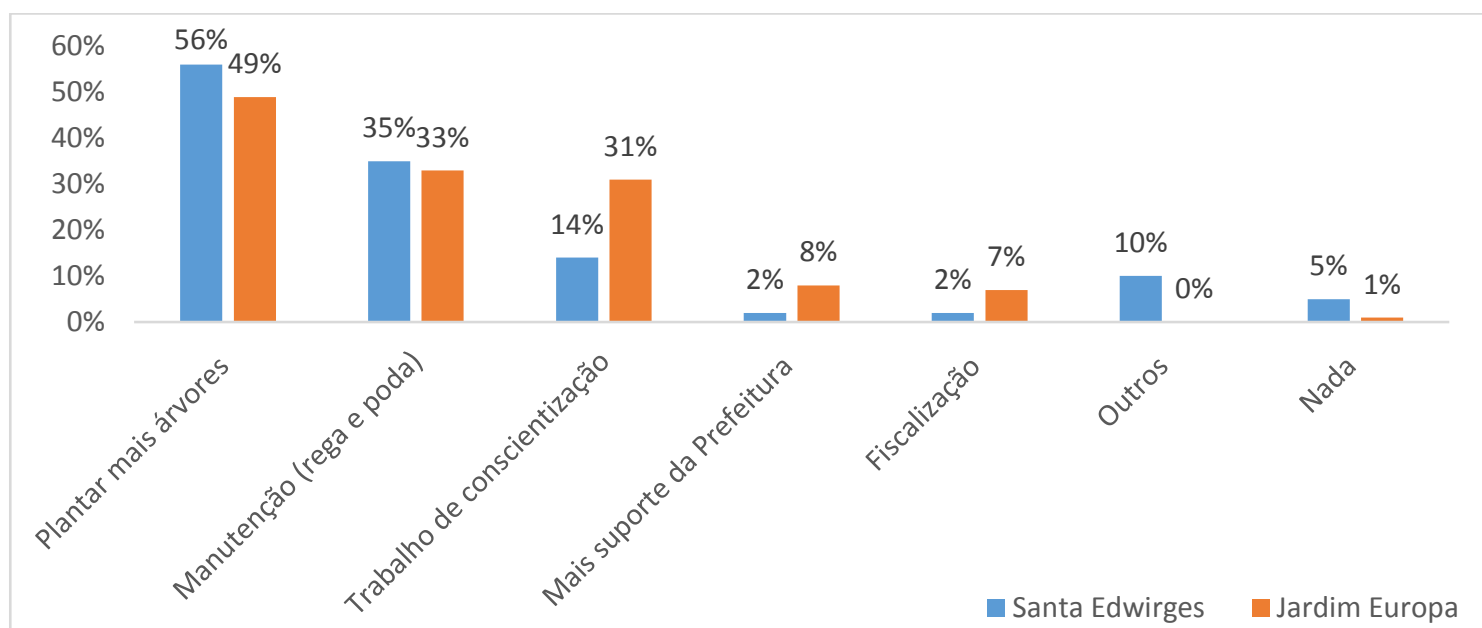

Figura 6 - Principais ações necessárias para promoção da arborização urbana segundo os moradores dos bairros analisados do município de Bauru-SP

Figure 6 - Main actions required for urban forest promotion according to the residents of the analyzed neighborhoods in the city of Bauru-SP 
Grande parte dos entrevistados (48\%), de ambos os bairros, não tinha conhecimento se havia uma lei específica em Bauru relacionada à arborização urbana. Entretanto, no Parque Jardim Europa, considerado o bairro com moradores de maior poder aquisitivo em relação ao outro bairro pesquisado, a quantidade de entrevistados que não sabia sobre a lei foi superior: $63 \%$, contra $58 \%$ do Parque Santa Edwiges. Muitos dos que afirmaram conhecer a lei de arborização urbana, em sentido amplo (Lei Municipal $n^{\circ}$ 4368/1999), têm esse conhecimento devido à necessidade de buscar os órgãos responsáveis quando é necessária a supressão de uma árvore. Estes moradores também sabem da obrigatoriedade de se ter uma árvore plantada na frente de suas casas; conhecimentos esses que foram adquiridos diante de situações irregulares que geraram algum tipo de sanção.

Uma das questões se relacionava sobre a "possibilidade de a população contribuir financeiramente para a promoção da arborização urbana". Para essa resposta não foi atribuído valores econômicos e nem como seria essa contribuição, apenas se a contribuição seria ou não possível. Observou-se uma divergência entre as opiniões em cada bairro. 62\% dos moradores do Parque Jardim Europa disseram que contribuiriam. Já no Santa Edwiges, o índice foi menor: $45 \%$ das pessoas afirmaram que poderiam ajudar financeiramente. Os moradores que não contribuiriam alegaram não ter condição financeira ou justificaram que já pagavam muitos impostos aos órgãos responsáveis por tal ação.

Quando questionados sobre a possibilidade de ganharem uma muda de árvore para plantar em algum local, 53\% dos entrevistados do Parque Jardim Europa responderam que gostariam de receber, enquanto que no Parque Santa Edwiges 50\% dos moradores desejaram ganhar a planta. A maioria dos entrevistados que respondeu que não gostaria de receber a muda de árvore justificou que não havia espaço em sua casa, porque já tinha uma árvore na frente do imóvel ou em razão da calçada ser pequena.

Perante o exposto, é recomendável a criação de programas que orientem a população no que tange a arborização urbana, com objetivo de proporcionar aos moradores acesso às informações para, assim, evitar futuros problemas envolvendo este assunto.

\section{CONCLUSÕES}

A percepção da arborização entre os bairros foi distinta, sendo que $59 \%$ dos moradores entrevistados no bairro Parque Jardim Europa mostraram possuir conhecimento sobre arborização, contra 38\% dos entrevistados no bairro Parque Santa Edwiges. 
O plantio de mais árvores foi o item mais apontado em ambos os bairros como processo de melhorias relativas à arborização urbana, mas devido a um menor poder aquisitivo no bairro Parque Santa Edwiges, os moradores não demostraram vontade em contribuir economicamente, acreditando que isso é uma responsabilidade majoritária da Prefeitura. As vantagens e desvantagens apontadas não diferiram significativamente entre os bairros. Acredita-se que algumas das divergências apontadas no presente estudo podem estar relacionadas à escassez de ações do poder público local em relação à arborização urbana, ao grau de instrução dos moradores e do poder aquisitivo.

\section{AGRADECIMENTOS}

Gostaríamos de agradecer as correções e sugestões dos revisores bem como à Mirian Cury pelas melhorias no manuscrito.

\section{REFERÊNCIAS}

BOBROWSKI, R.; BIONDI, D. Percepção e preferência popular por atributos estéticos e ecológicos na composição da arborização de ruas. Revista Floresta. Curitiba, v.46, n. 1, p.123-133, 2016.

GROSS, A.; DORS, P.; CAMPOS, K. A.; SILVA, A. C.; HIGUCHI, P. Percepção dos moradores e avaliação da arborização em bairros periféricos na cidade de Lages, SC.

Revista da Sociedade Brasileira de Arborização Urbana. Piracicaba, v. 7, n. 2, p. 24-36. 2012.

IBGE - Instituto Brasileiro de Geografia e Estatística. Censo 2017. Disponível em: <http://www.ibge.gov.br>. Acesso em: 24 de fev. de 2018.

IBGE - Instituto Brasileiro de Geografia e Estatística. Censo 2010. Disponível em: < https://censo2010.ibge.gov.br/sinopseporsetores/>. Acesso em: 02 de abr. de 2019.

LOURENÇO, J. S. G. Percepção da população sobre a arborização da cidade de São João Del-Rei, Minas Gerais. Revista da Sociedade Brasileira de Arborização Urbana. Piracicaba, v. 12, n. 2, p. 62-72, 2017.

MOSER, P.; SILVA, A. C.; HIGUCHI, P. Arborização urbana: um encontro da natureza com o meio urbano. Espiral. São Paulo, v. 42, n.1, p. 1-10, 2010.

OLIVEIRA, V. P.; DIAS, J. G. S.; RIBEIRO, A. T.; OLIVEIRA, L. B. S.; MARIANO, M. O.; Pinto, D. S. A percepção da população sobre arborização em um conjunto habitacional no município de Paragominas-PA. Revista da Sociedade Brasileira de Arborização Urbana. Piracicaba, v.12, n.3, p. 27-36, 2017.

PINHEIRO, C. R.; SOUZA, D. D. A importância da arborização nas cidades e sua influência no microclima. Revista Gestão \& Sustentabilidade Ambiental, Chapecó v. 6, n. 1, p. 67 82, 2017. 
PIZZIOLO, B. V.; TOSTES, R.; SILVA, K.; ARRUDA, V. M. Arborização urbana: Percepção ambiental dos moradores dos bairros Bom Pastor e Centro da cidade de Ubá/MG. Revista Eletrônica em Gestão, Educação e Tecnologia Ambiental-REGET, Santa Maria, v. 18, n. 3, p. 1162-1169, 2014.

QUADROS, L. S.; FREI, F. Percepção ambiental dos residentes da cidade de Assis-SP com relação à arborização viária da Avenida Rui Barbosa. REVSBAU, Piracicaba, v. 4, n. 2, p. 16-34, 2009.

RODRIGUES, T. D.; MALAFAIA, G.; QUEIROZ, S. E. E.; RODRIGUES, A. S. L. Percepção sobre arborização urbana de moradores em três áreas de Pires do Rio - Goiás. Revista de Estudos Ambientais, Blumenau, v. 12, n. 2, p.47-61, 2010.

ROPPA, C.; FALKNBERG, J.R; STANGERLIN, D.M.; BRUN, F.G.K.; BRUN, E.J.; LONGHI, S.J. Diagnóstico da percepção dos moradores sobre a arborização Urbana na Vila Estação Colônia - Bairro Camobi, Santa Maria - RS. Revista da Sociedade Brasileira de Arborização Urbana, Piracicaba v.2, n.2, p.11-30. 2007.

SANTOS, M.O.; MAIA, L.P.S.S.; OLIVEIRA, E.D.; NETO, J.C.A.S.; CELLA, W. Percepção ambiental sobre a arborização urbana no bairro Santa Tereza, Tefé, Amazonas, Brasil. Revista RaeGa, Curitiba, v.44, p. 231-241, 2018.

SHAMS, J. C. A.; GIACOMELI, D. C.; SUCOMINE, N. M. Emprego da arborização na melhoria do conforto térmico nos espaços livres públicos. Revista da Sociedade Brasileira de Arborização Urbana, Piracicaba, v. 4, n. 4, p. 1-16, 2009.

SILVA, E. C. R.; ALVES, F. B.; SILVA, I. I. S.; CARVALHO, B. C.; ALMEIDA, J. M.; MAGALHÃES, R. C. Percepção da população quanto à arborização na zona central histórica de Altamira-PA. Revista da Sociedade Brasileira de Arborização Urbana, Curitiba, v. 10, n. 3, p. 24-37, 2015.

SILVA, R. V.; REGO, A. M. T.; COSTA, T. S.; SILVA, D. G.; TOSTES, R. B. Percepção ambiental dos moradores de Visconde de Rio Branco - MG, em relação à arborização urbana. Revista da Sociedade Brasileira de Arborização Urbana, Curitiba, v.9, n.3, p 108-121, 2014.

SOUZA, S. M.; CARDOSO, A. L.; SILVA, A. G. Estudo da percepção da população sobre a arborização urbana, no município de Alegre-ES. Revista da Sociedade Brasileira de Arborização Urbana. Piracicaba, v. 8, n. 2, p. 68-85, 2013.

SOUZA, M.A.S.; SOUTO, P.C.; FERNANDES, S.P.S.; NEVES, A.A.; LIMA, F.; SOUTO, J.S. Percepção da população relacionada à arborização urbana de praças no centro da cidade de Patos-PB. Agropecuária Científica no Semiárido, Patos, v.12, n.4, p.368-375, 2016. 